\title{
Glucocorticoids Exacerbate Cognitive Deficits in TDP-25 Transgenic Mice via a Glutathione-Mediated Mechanism: Implications for Aging, Stress and TDP-43 Proteinopathies
}

\author{
Antonella Caccamo, David X. Medina, and Salvatore Oddo \\ Department of Physiology and The Barshop Institute for Longevity and Aging Studies, University of Texas Health Science Center at San Antonio, San \\ Antonio, Texas 78229
}

\begin{abstract}
The accumulation of TDP-43 (transactive response DNA-binding protein 43) and its $25 \mathrm{kDa}$ C-terminal fragment (TDP-25) is a hallmark of several neurodegenerative disorders, including frontotemporal lobar degeneration (FTLD-TDP) and amyotrophic lateral sclerosis (ALS). The majority of FTLD-TDP cases are due to loss of function mutations in the gene encoding progranulin, a secreted growth factor. In ALS, specific mutations in the gene encoding TDP-43 have been linked to the disease pathogenesis. In both cases, however, the penetrance of the mutations greatly increases during aging, suggesting that other genetic or environmental factors may facilitate the development of the disease. Using transgenic mice that overexpress the $25 \mathrm{kDa}$ C-terminal fragment of TDP-43, here we show that glucocorticoids, stress hormones known to increase the brain susceptibility to neurotoxic insults, increase the levels of soluble TDP-25 and exacerbate cognitive deficits, without altering full-length TDP-43 levels. Additionally, we show that the mechanism underlying the glucocorticoid-mediated increase in TDP-25 levels is coupled to changes in the glutathione redox state. Glutathione is an antioxidant involved in protecting cells from damage caused by reactive oxygen species; notably, alterations in the ratio of reduced to oxidized glutathione, which is the primary determinant of the cellular redox state, are associated with aging and neurodegeneration. We show that restoring the ratio of reduced to oxidized glutathione blocks the glucocorticoid effects on TDP-25. These data show that glucocorticoids potentiate the neurotoxic action of TDP-25 by increasing its levels and clearly indicate the role of cellular oxidative damage in this process.
\end{abstract}

\section{Introduction}

TDP-43 (transactive response DNA-binding protein 43) is a ubiquitously expressed nuclear protein encoded by the TARDBP gene on chromosome 1. It is involved in exon skipping, alternative splicing, mRNA stabilization and in linking different types of nuclear bodies (I.F. Wang et al., 2002, H.Y. Wang et al., 2004; Buratti and Baralle, 2008). In addition to its nuclear functions, TDP-43 also plays a role in synaptic plasticity; indeed, TDP-43 is highly expressed in the hippocampus, colocalizes with PSD-95 (postsynaptic density-95) in dendritic spines following membrane depolarization, and is associated with actin and CaMKII mRNAs in dendrites (Lein et al., 2007; Wang et al., 2008).

The accumulation of TDP-43 is a hallmark feature of several neurodegenerative disorders, known as TDP-43 proteinopathies (Cohen et al., 2011a; Hasegawa et al., 2011). Specifically, TDP-43 has been identified as the pathological signature protein in frontotemporal lobar degeneration with ubiquitin-positive inclusions (FTLD-TDP) and in amyotrophic lateral sclerosis (ALS),

Received July 12, 2012; revised Nov. 12, 2012; accepted Nov. 15, 2012.

Author contributions: S.O. designed research; A.C. and D.X.M. performed research; A.C. and S.0. analyzed data; S.O. wrote the paper.

The authors declare no competing financial interests.

Correspondence should be addressed to Dr. Salvatore Oddo, Assistant Professor, Department of Physiology, University of Texas Health Science Center, San Antonio, 7703 Floyd Curl Drive, San Antonio, TX 78229-3900. E-mail: oddo@uthscsa.edu.

DOI:10.1523/JNEUROSCI.3314-12.2013

Copyright $\odot 2013$ the authors $\quad 0270-6474 / 13 / 330906-08 \$ 15.00 / 0$ two neurodegenerative disorders with overlapping clinical and neuropathological features (Neumann et al., 2006; Geser et al., 2010). In addition, TDP-43-positive inclusions are present in Parkinson disease, dementia with Lewy bodies, and $\sim 30 \%$ of Alzheimer disease cases. Pathological TDP-43 translocates from its normal nuclear location to the cytoplasm where it forms insoluble inclusions (Neumann et al., 2006). Additionally, during the disease process, TDP-43 becomes hyperphosphorylated, ubiquitinated and cleaved to generate C-terminal fragments that accumulate only in affected brain regions (Neumann et al., 2006; Igaz et al., 2008). Transgenic mice selectively overexpressing the $25 \mathrm{kDa}$ C-terminal fragment of TDP-43 (herein referred to as TgTDP-25) develop neuropathological and behavioral features of FTLD-TDP (Caccamo et al., 2012).

The majority of TDP-43 proteinopathies are sporadic, suggesting that environmental factors may contribute to the disease pathogenesis. Along these lines, even in cases in which there is a clear genetic cause (e.g., mutations in progranulin or in the TARDBP gene), the disease develops as a function of age, further highlighting that changes occurring during normal aging may precipitate the development of the disease. Nevertheless, little is known about age-dependent changes that may influence the onset and progression of TDP-43 proteinopathies. Glucocorticoid hormones are secreted from the adrenal gland during stress (Sarabdjitsingh et al., 2012), increase neuronal susceptibility to a variety of neurotoxic insults including amyloid- $\beta(\mathrm{A} \beta)$, hypoglycemia, and hypoxia (Sapolsky, 1996; Reagan and McEwen, 1997). 
For example, glucocorticoids intensify $\mathrm{A} \beta$ and tau pathology in animal models of neurodegeneration (Green et al., 2006; Puccio et al., 2011; Sotiropoulos et al., 2011; Yao et al., 2011). Notably, glucocorticoids also facilitate the accumulation of reactive oxygen species (ROS), which have been linked to several neurodegenerative disorders, including TDP-43 proteinopathies (Meyerowitz et al., 2011; Cohen et al., 2011b; Iguchi et al., 2012). The effects of glucocorticoids on ROS levels may be mediated by a decrease in the activity of antioxidant enzymes such as the glutathione peroxidase (McIntosh et al., 1998; Patel et al., 2002). Although glucocorticoid levels increase as a function of age and have been implicated in brain aging (Garrido, 2011), their role in TDP-43 proteinopathies is not known.

\section{Materials and Methods}

Mice and treatment

The development of the TgTDP-25 mice was described previously (Caccamo et al., 2012). Briefly, the last 199 aa of the gene encoding TDP-43 were cloned under the control of a neuronal specific promoter and injected into oocytes from C57BL/6 mice. Two independent transgenic lines were obtained, indicated as $\mathrm{B}$ and $\mathrm{F}$, which have high and low expression levels of the transgene, respectively. Only the TgTDP25(B) mice are used in this work as we have previously shown behavioral deficits in both transgenic lines clearly indicating that the cognitive impairments in the TgTDP-25 mice were not simply due to an effect of integration of the transgene (Caccamo et al., 2012). Transgenic and nontransgenic (NonTg) mice ( $n=12 /$ genotype/drug group, equal number of males and females) received daily intraperitoneal injections of $5 \mathrm{mg} / \mathrm{kg}$ dexamethasone, a synthetic glucocorticoid (Sigma-Aldrich) or PBS for 2 weeks. For the rescue experiments, TgTDP-25 mice received daily intraperitoneal injections of $5 \mathrm{mg} / \mathrm{kg}$ dexamethasone, $5 \mathrm{mg} / \mathrm{kg}$ dexamethasone $+100 \mathrm{mg} / \mathrm{kg} \alpha$-lipoic acid, or PBS alone.

\section{Morris water maze}

The spatial version of the Morris water maze (MWM) was conducted as detailed by Clinton et al. (2007). Both learning and probe trials were recorded by a video camera mounted on the ceiling; data were analyzed off-line using the EthoVisionXT tracking system (Noldus).

\section{Protein extraction and Western blots}

Upon the completion of the behavioral experiments, mice were killed by $\mathrm{CO}_{2}$ asphyxiation and cervical dislocation and their brains were quickly removed and cut midsagittally. One hemibrain was drop-fixed in 4\% paraformaldehyde and used for immunohistochemistry. The other hemibrain was frozen in dry ice for biochemical analyses. For selected experiments, proteins were extracted from hippocampal fractions as detailed in Results and figure legends.

Protein extraction in buffers of increasing stringency was performed as detailed by Caccamo et al. (2010a). Hemibrains were homogenized with a power homogenizer in $1 \mathrm{ml}$ of low-salt buffer (10 mM Tris, pH 7.5, $5 \mathrm{~mm}$ EDTA, $1 \mathrm{~mm}$ DTT, 10\% Sucrose) containing protease inhibitors and centrifuged at $14,400 \mathrm{rpm}$ for $30 \mathrm{~min}$ at $4^{\circ} \mathrm{C}$. The supernatant was stored at $-80^{\circ} \mathrm{C}$ as low-salt fraction while the pellet was rehomogenized in high-salt solution (low-salt buffer plus $1 \%$ Triton X-100 and $0.5 \mathrm{M} \mathrm{NaCl}$ ), in the presence of protease inhibitors and centrifuged at 20,000 $\mathrm{rpm}$ for $1 \mathrm{~h}$ at $4^{\circ} \mathrm{C}$. The supernatant was stored at $-80^{\circ} \mathrm{C}$ as high-salt fraction. The pellet underwent further sequential extraction in Sarkosyl buffer (low salt $+1 \%$ Sarkosyl $+0.5 \mathrm{M} \mathrm{NaCl})$ and in urea buffer ( $7 \mathrm{M}$ urea, $2 \mathrm{~m}$ thiourea, $4 \%$ CHAPS, 30 mм Tris).

To obtain the cytosolic and nuclear fractions, brains were washed in PBS and then homogenized in a Dounce homogenizer with $2 \mathrm{ml}$ of solution A (10 mм HEPES, pH 7.9, 10 mм KCL, 0.1 mm EDTA, $0.1 \mathrm{~mm}$ EGTA, $1 \mathrm{~mm}$ DTT) in the presence of protease inhibitors and $0.5 \%$ NP40, for a total of 10 strokes. The solution was then kept on ice for $10 \mathrm{~min}$ and centrifuged $1 \mathrm{~min}$ at 11,000 rpm. The supernatant was removed and stored at $-80^{\circ} \mathrm{C}$ as cytosolic fraction. The pellet was resuspended in 250 $\mu$ of Solution B (20 mм HEPES, pH 7.9, 400 mм NaCl, 1 mм EDTA, 1 mM EGTA, 1 mM DTT) in the presence of protease inhibitors and placed on ice for $15 \mathrm{~min}$. Samples were then centrifuged $5 \mathrm{~min}$ at $11,000 \mathrm{rpm}$ and the supernatant was stored at $-80^{\circ} \mathrm{C}$ as nuclear fraction. Western blot experiments were run as previously described (Oddo et al., 2007).

\section{Antibodies}

The following antibodies were used: TARDBP Antibody (Proteintech), 1:1000; Anti-Ubiquitin (EMD Millipore), 1:500; Anti-phospho TDP-43 (EMD Millipore), 1:1000; anti-histone H1 (Abcam), 1:1000; anti-actin (Sigma), 1:15,000; anti-LC3-1, LC3-II and Atg7 (Cell Signaling Technology), 1:1000.

\section{Glutathione measurements}

Total glutathione. To measure the levels of total glutathione hemibrains were homogenized in $1 \mathrm{ml}$ of cold 5\% methaphosphoric acid and then centrifuged at $4^{\circ} \mathrm{C}$ for $30 \mathrm{~min}$ at $14,000 \mathrm{rpm}$. The supernatant was used for the assay, which was prepared in a 96 well plate. Changes in absorbance were measured using a microplate reader (Synergy HT, BioTek) at $405 \mathrm{~nm}$ for $60 \mathrm{~s}$.

Reduced/oxidized glutathione ratio. To measure the ratio between reduced (GSH) and oxidized (GSSG) glutathione, we used a luminescentbased assay (Promega) and followed the instruction manual. Specifically, tissue was homogenized with $1 \mathrm{ml}$ of $5 \%$ sulfosalicylic acid using a Dounce pestle. The homogenates were then centrifuged at $4^{\circ} \mathrm{C}$ for $30 \mathrm{~min}$ at $14,000 \mathrm{rpm}$. The assay was prepared in white opaque 96 well plates to minimize well-to-well cross talk. Luminescence was read using a microplate reader (Synergy HT, BioTek) with an integration time of $1 \mathrm{~s}$ per well.

\section{Proteasome activity assay}

This assay was performed as previously described (Medina et al., 2011). Specifically, $10 \mu \mathrm{l}$ of brain homogenate were incubated with 75 $\mu \mathrm{M}$ proteasomal substrates Suc-LLVY-AMC, Bz-VGR-AMC and Z-LLE-AMC (Enzo Life Sciences), which probe for chymotrypsinlike, trypsin-, and peptidylglutamyl-peptide hydrolyzing-like (PGPH) activities, respectively. Reactions were performed in assay buffer $(25 \mathrm{mM}$ HEPES, pH 7.5, 0.5 mm EDTA, 0.05\% NP-40) in a total of $200 \mu \mathrm{l}$ in black 96 -well plates. Substrates were added immediately before readings. Kinetic readings were taken at $37^{\circ} \mathrm{C}$ every $1.5 \mathrm{~min}$ for $60 \mathrm{~min}$ (excitation $360 \mathrm{~nm}$, emission $460 \mathrm{~nm}$ ) using the Synergy HT multimode microplate reader using the Gen 5 software (BioTek). Readings were normalized to protein concentration.

\section{Real-time PCR}

These experiments were conducted as described previously (Caccamo et al., 2012). Briefly, total RNA was extracted using the RT ${ }^{2}$ qPCR-Grade RNA Isolation Kit (SABiosciences) according to the manufacturer's protocol. One microgram of total RNA was used to make the cDNA by using $\mathrm{RT}^{2}$ First Strand Kit in a total volume of $20 \mu \mathrm{l}$ according to the manufacturer's protocol. After RT-PCR, $1 \mu \mathrm{l}$ of cDNA was amplified and quantified in 96 well plates using ABI Prism 7000 sequence detection (Applied Biosystems). The relative DNA levels were normalized to the reference housekeeping gene presenilin 1 .

\section{Statistical analyses}

Data were analyzed as we previously detailed (Caccamo et al., 2010b). Briefly, one-way and two-way ANOVAs were performed using GraphPad Prism. Post hoc Bonferroni test was then used to determine individual differences among groups. The Student's $t$ test was used when suitable.

\section{Results}

To determine the effects of repeated glucocorticoid exposure on TDP-43 neuropathology, we used a mouse model of FTLD-TDP that we recently developed by overexpressing the C-terminal fragment of TDP-43. These mice, herein referred to as TgTDP25 , develop age-dependent cognitive deficits associated with the accumulation of soluble TDP-25 (Caccamo et al., 2012). We reported the generation of two independent lines, with the B line showing more robust behavioral deficits, which are detectable at 

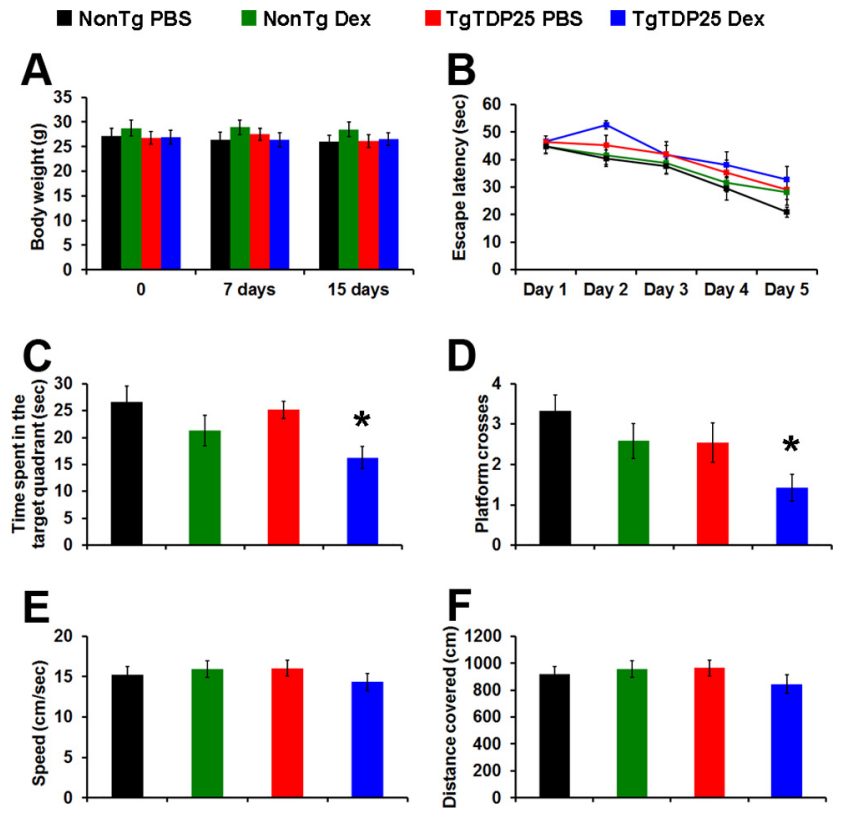

Figure 1. Dexamethasone exacerbates spatial memory deficits in TgTDP-25 mice. A, Body weight of the mice was recorded at the beginning of the treatment, and 7 and $14 \mathrm{~d}$ after. No significant weight changes were observed among the groups during the 2 weeks of treatment $(p>0.05)$. B , Six-month-old TgTDP-25 and NonTg mice received four training trials per day for $5 \mathrm{~d}$ in the spatial version of the Morris water maze. The learning curves indicate the escape latency of each age group across the $5 \mathrm{~d}$ of training. Each time-point represents the average escape latency for the four training trials of that specific day. Mice significantly learned the task as indicated by a reduced time to find the hidden platform $(F=19.01 ; p<0.0001)$. Bonferroni's post hoc analysis showed that all groups learned at the same pace. $C, D$, Reference memory, measured $24 \mathrm{~h}$ after the last training trial, was significantly worse in the TgTDP- 25 mice treated with dexamethasone compared with the other three groups. $\boldsymbol{E}, \boldsymbol{F}$, Swimming speed and distance traveled during the probe trials were not significantly different among the four groups of mice. The data are presented as means \pm SEM and were analyzed by two-way ANOVA. $n=$ 12/genotype/drug group.

6 months of age (Caccamo et al., 2012). Here, we focused on assessing the role of elevated glucocorticoids on the onset of cognitive deficits in the high expressing line. Toward this end, 6-month-old TgTDP-25 and NonTg mice received daily intraperitoneal injections of dexamethasone $(5 \mathrm{mg} / \mathrm{kg})$ or PBS $(n=$ $12 /$ genotype/drug group) for 2 weeks. This treatment paradigm has been used previously to modulate glucocorticoid function in rodent brains (Terzic et al., 2003; Green et al., 2006). We monitored the overall health of the mice during the 2 weeks of treatment and did not detect any gross adverse effects or significant changes in their body weight, which was measured immediately before the beginning of the treatment, after 1 week and upon the completion of treatment (Fig. 1A).

To determine the effects of dexamethasone on learning and memory, during the last week of treatment, mice were trained in the spatial version of the MWM. Specifically, mice received 4 training trials per day for 5 consecutive days to learn to find a hidden platform using extra maze cues. Their performance was analyzed using a mixed-model, repeated-measures ANOVA, with treatment and genotype as the categorically fixed effects, days as the numeric covariate, animals as the random effect, and escape latency as the dependent variable. We found a significant effect for days $(F=19.01 ; p<0.0001)$, indicating that the mice learned the task across sessions (Fig. 1B). However, we found a nonsignificant genotype/treatment-day interaction $(F=0.41$; $p>0.05)$, indicating that there was no difference in the pace of learning among the four different groups (Fig. 1B). Twenty-four hours after the last training trial, we tested spatial memory by measuring the time mice spent in the target quadrant and the number of platform location crosses over a $60 \mathrm{~s}$ probe trial. Oneway ANOVA indicated significant changes in the time the mice spent in the target quadrant and the number of platform location crosses (Fig. $1 C, D ; p=0.015$ and $p<0.018$, respectively). A post hoc test with Bonferroni correction showed that the TgTDP-25 mice treated with dexamethasone performed significantly worse in both measurements compared with the TgTDP-25 mice injected with PBS in both tasks $(p<0.05)$. In contrast, dexamethasone exerted no effects on NonTg mice (Fig. 1C,D). To determine whether the physical performance of the mice may account for the changes in spatial memory, we measured the swim speed and the distance mice traveled during the probe trials and found that both parameters were similar among the four groups of mice as indicated by one-way ANOVA (Fig. 1E,F). Together, these findings clearly indicate that dexamethasone leads to spatial memory deficits in the TgTDP-25 mice.

To start understanding the molecular mechanisms underlying the dexamethasone-induced memory deficits in the TgTDP-25 mice, we measured TDP-43 and its C-terminal fragments in buffers of increasing strength. In the low-salt fraction, we found that the steady-state levels of full-length TDP-43 were similar between transgenic and nontransgenic mice, independent of the dexamethasone treatment (Fig. $2 A, B$ ). In contrast, we found that in the TgTDP-25 mice, dexamethasone administration significantly increased the levels of TDP-25 ( $p<0.05$; Fig. $2 A, C)$. Similarly, in the high-salt fraction, we found no changes in fulllength TDP-43 levels but a significant increase in TDP-25 levels in the dexamethasone-treated transgenic mice compared with PBS-treated mice (Fig. 2D-F). The TDP-25 fragment was not detectable in the Sarkosyl and urea fractions. Together, these data suggest that dexamethasone selectively increases the steady-state levels of soluble TDP-25 in transgenic mice, which is consistent with the exacerbation in memory deficits seen in these mice (Fig. 1).

In FTLD-TDP and in other related TDP-43 proteinopathies, TDP-43 is mislocalized from its nuclear location to the cytosol. We have previously reported that in the TgTDP-25 mice, overexpression of the $25 \mathrm{kDa}$ C-terminal fragment of TDP-43 was sufficient to alter endogenous TDP-43 processing and distribution between nucleus and cytoplasm (Caccamo et al., 2012). To determine the effect of dexamethasone treatment on the cellular localization of TDP-43, we extracted nuclear and cytosolic fractions from brains of TgTDP-25 and NonTg mice treated with dexamethasone or PBS. The majority of TDP-43 was in the nuclear fraction (Fig. $3 A, B$ ), consistent with the notion that TDP-43 is normally localized in the nucleus (Lee et al., 2012). Notably, dexamethasone did not alter the levels of full-length TDP-43 in the nucleus or cytosol (Fig. $3 A, B$ ). In contrast, we found that in the transgenic mice, dexamethasone treatment significantly increased the levels of TDP-25 in both nucleus and cytosol (Fig. $3 A, C)$. These results show that dexamethasone did not alter the distribution of TDP-43 and its C-terminal fragments between nucleus and cytosol. However, there was a general increase in TDP-25 levels in the transgenic mice treated with dexamethasone compared with transgenic mice treated with PBS in both intracellular compartments.

To analyze the mechanisms underlying the dexamethasonemediated increase in TDP-25 levels, we first assessed whether dexamethasone altered the expression of the TDP-25 transgene by measuring TDP-25 mRNA levels using real-time PCR. We found that dexamethasone administration did not change the 

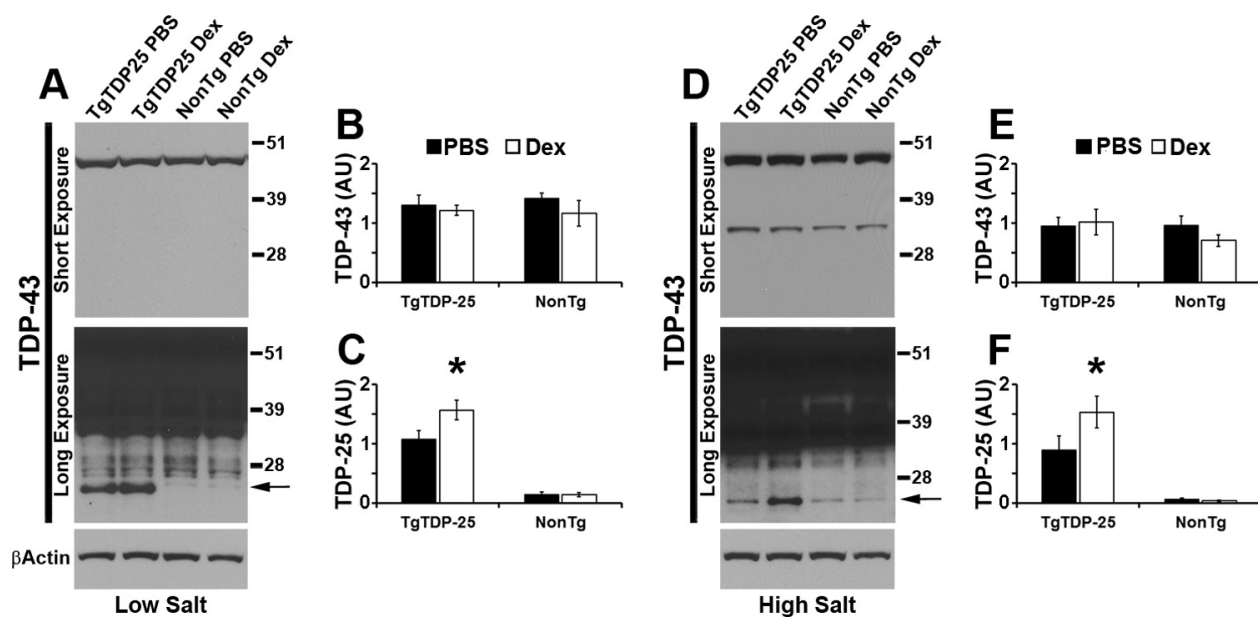

Figure 2. Dexamethasone-mediated increase in soluble TDP-25 levels. $A$, Representative Western blots of proteins extracted from whole hemi-brain (without cerebellum) of treated and untreated mice, in low-salt buffer. Two different exposure times are presented to show the less abundant, low molecular weight bands. B, Quantitative analyses of the blots from low-salt extraction show that the levels of full-length TDP-43 were similar between the transgenic and NonTg mice, regardless of the treatment group. C, In contrast, we found that dexamethasone significantly increased the steady-state levels of TDP-25 (arrow in the bottom blot). D, Representative Western blots of proteins extracted from treated and untreated mice in high-salt buffer. Two different exposure times are presented to show the less abundant, low molecular weight bands. E, Quantitative analyses of the blots from high-salt extracts show that the levels of full-length TDP-43 were similar between transgenic and nontransgenic mice, regardless of treatment. F, TDP-25 levels were significantly higher in TgTDP-25 mice treated with dexamethasone compared with genotype-matched micetreated with PBS (arrow in thebottom blot). $n=8 / \mathrm{genotype} /$ treatment group . ${ }^{*} p<0.05$. $\beta$-Actin was used as a loading control and quantifications of the Western blots were done by normalizing the protein of interest to $\beta$-Actin. Data are presented as means \pm SEM and analyzed by two-way ANOVA, with genotype and treatment as independent variables. Blots were probed with an anti-TDP-43 polyclonal antibody from Proteintech.
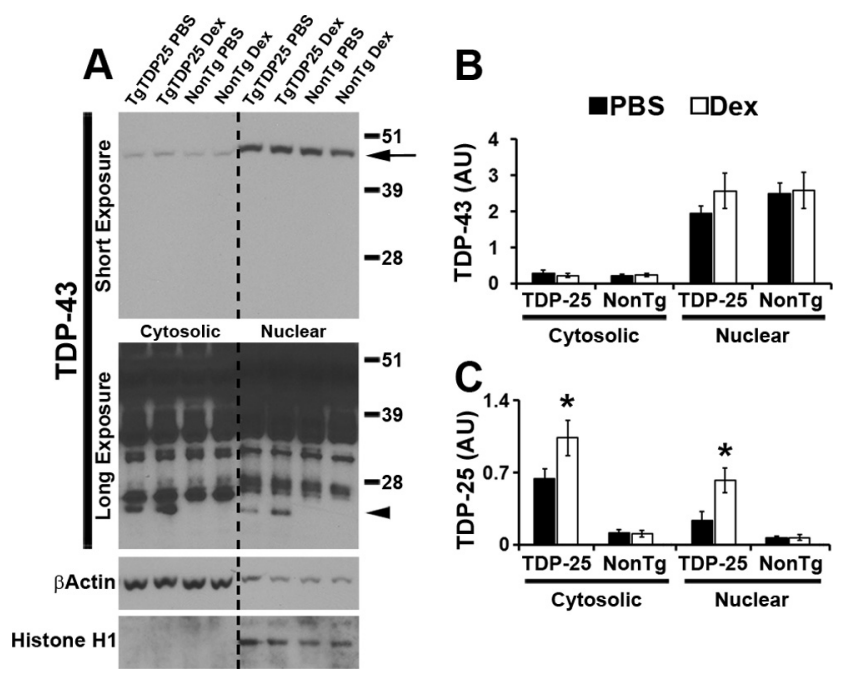

Figure 3. Dexamethasone increased TDP-25levels in both the nuclear and the cytosolicfraction. $A$, Representative Western blots of protein extracted from hemi-brain (without cerebellum) TgTDP-25 and NonTg mice treated with dexamethasone (Dex) or PBS. Different exposures are presented to show the less abundant, low molecular weight TDP-43 fragments. Proteins were extracted from the cytosolic and nuclear fractions, as depicted in the figure. TDP-43 blots were probed with an anti-TDP-43 polyclonal antibody from Proteintech. $\beta$-Actin and Histone $\mathrm{H} 1$ were used as loading controls for the cytosolic and nuclear fractions, respectively. $\boldsymbol{B}$, As expected, quantitation of the full-length TDP-43 band (arrow in the top blot of $\boldsymbol{A}$ ) shows that the levels of TDP-43 are significantly higher in the nucleus compared with the cytoplasm in both transgenic and NonTg mice, regardless of treatment group. Additionally, dexamethasone did not alter the levels of TDP-43 in the cytosolic or nuclear fractions of TgTDP-25 and NonTg mice. C, Quantitative analysis of the $25 \mathrm{kDa}$ band (arrowhead in the bottom blot in A) shows that in the TgTDP-25 mice, dexamethasone significantly increased TDP-25 levels in both the cytosolic and nuclear fractions. ${ }^{*} p<0.05$. Quantifications of the Western blots were done by normalizing the fragment of interest to $\beta$-Actin or Histone H1. Data are presented as means \pm SEM and analyzed by two-way ANOVA, with genotype and treatment group as independent variables. $n=8 /$ genotype/treatment group.

expression of the transgene as indicated by similar threshold values $(10.25 \pm 2.2$ and $12.25 \pm 3.1$ for dexamethasone-treated and untreated mice, respectively). A Student's $t$ test analysis indicated that these values were not statistically significant from each other.
Given that an increase in TDP-25 expression was not likely to be responsible for the dexamethasone-increase in TDP-25 pathology, we next focused on TDP-25 turnover. The proteasome and autophagy represent the two major cellular protein degradation systems and are known to be involved in TDP-25 metabolism (Caccamo et al., 2009; Urushitani et al., 2010; Wang et al., 2010; Bose et al., 2011; Brady et al., 2011; Wang et al., 2012). First, we used the fluorogenic substrates Bz-VGR-AMC, Suc-LLVYAMC and Z-LLE-AMC to measure chymotrypsin-like, trypsinlike, and PGPH activities of the proteasome in the brain of treated and untreated TgTDP-25 mice. We found no statistically significant changes in these activities between these two groups of mice (Fig. 4A), suggesting that most likely the proteasome is not involved in the dexamethasone-mediated increase in TDP-25 levels. Next, we assessed autophagy induction by measuring the levels of the autophagy-related proteins Atg7 (which is necessary for autophagy induction) and LC3, which is an indicator of autophagy induction (Mizushima et al., 1998; Ohsumi, 2001; Suzuki et al., 2001) Toward this end, LC3-I is post-translationally modified during autophagy induction to form LC3-II, which is incorporated into the growing autophagosome membrane (Mizushima et al., 1998; Ohsumi, 2001; Suzuki et al., 2001). We found that the levels of Atg7 were significantly decreased in the brains of the TgTDP-25 mice treated with dexamethasone compared with TgTDP-25 mice treated with vehicle (Fig. 4B,C). Similarly, LC3-II levels were significantly lower following dexamethasone administration (Fig. $4 B, C$ ). These data, together with published reports showing that autophagy is involved in TDP-25 metabolism, suggest that changes in autophagy following dexamethasone administration may account for the increase in TDP-25 levels.

We next sought to better understand the link between dexamethasone and the decrease in autophagy induction. Glucocorticoids increase the brain susceptibility to a variety of neurotoxic insults. One mechanism by which glucocorticoids mediate these effects is by reducing the activity of the antioxidant enzyme, glutathione peroxidase (Patel et al., 2002). To function properly, this 

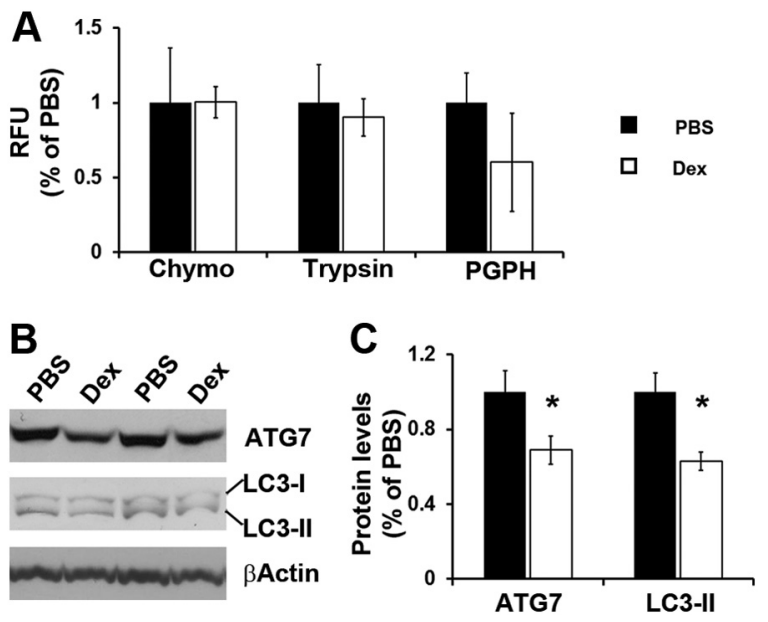

Figure 4. Dexamethasone impairs autophagy induction. $\boldsymbol{A}$, Whole hemi-brain homogenates (without cerebellum) from PBS- and dexamethasone (DEX)-treated TgTDP-25 mice were analyzed for proteasome activity. The data show that dexamethasone did not alter the chymotrypsin- and trypsin-like activities, nor did it change the peptidylglutamyl-peptide hydrolyzing (PDPH) activity. $\boldsymbol{B}$, Representative Western blots of proteins extracted from brain homogenates of PBS and DEX-treated TgTDP-25 mice. C, Quantitative analyses of the blots show that the levels of the autophagy related proteins Atg7 were significantly decreased following dexamethasone administration. Further, the LC3-II levels were significantly lower in the dexamethasone-treated TgTDP-25 mice compared with mice treated with PBS only. $\beta$-Actin was used as a loading control and quantifications of the Western blots were done by normalizing the protein of interest to $\beta$-Actin. Data are presented as means \pm SEM and analyzed by Student's $t$ test. Chymo, Chymotrypsin.

enzyme needs a suitable amount of GSH, which serves as an electron donor. To determine whether changes in glutathione levels were involved in the dexamethasone-mediated changes in TDP-25 levels and cognitive deficits, we initially measured the levels of total glutathione, GSSG, and GSH in the brains of transgenic mice treated with dexamethasone and PBS. To quantitatively assess total glutathione levels, we used a commercially available kit which takes advantage of a simple reaction in which glutathione reductase reduces GSSG to GSH in the presence of NADPH. A specific chromogen reacts with the thiol group of GSH producing a compound that absorbs at $405 \mathrm{~nm}$. We followed the rate of glutathione production over $11 \mathrm{~min}$ and found that total glutathione production was $0.95 \pm 0.04$ and $0.91 \pm 0.01$ $\mu \mathrm{M} / \mu \mathrm{l}$ in TgTDP-25 mice treated with dexamethasone and TgTDP-25 mice treated with PBS, respectively. Student's $t$ test analysis indicated that these values were not statistically significant from each other. This result was not surprising as changes in the GSH/GSSG ratio, more than the total levels of glutathione, have been associated with aging and neurodegeneration (Ghezzi, 2005; Rebrin and Sohal, 2008; Ballatori et al., 2009). To determine whether dexamethasone administration altered the cellular redox state, we measured the ratio of reduced to oxidized glutathione using a commercially available luminescence-based system. In PBS-treated TgTDP-25 mice, the GSH/GSSG ratio was $16.56 \pm 2.12$. In contrast, the GSH/GSSG ratio in the dexamethasone-treated TgTDP-25 mice was significantly reduced $(10.20 \pm 0.52)$ in the brains of the TgTDP-25 mice treated with dexamethasone $(p=$ 0.03 ), indicating that the dexamethasone-treated brains overall are more susceptible to oxidation. Although there is clear evidence in the literature that oxidative damage impairs autophagy induction (Pivtoraiko et al., 2009), further studies are needed to dissect this link.

The data presented so far indicate that in the dexamethasonetreated brains there is a correlation between the decrease in the GSH/GSSG ratio and autophagy induction and the increase in
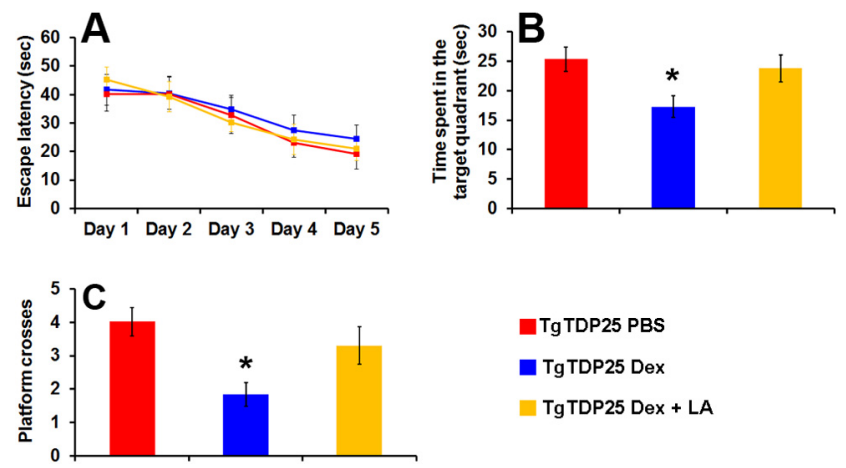

Figure 5. $\alpha$-lipoic acid prevents the dexamethasone-mediated memory deficits. $\boldsymbol{A}$, Six-monthold TgTDP-25 mice received four training trials per day for $5 \mathrm{~d}$ in the spatial version of the Morris water maze. The learning curves indicate the escape latency of each age group across the $5 \mathrm{~d}$ of training. Each time-point represents the average escape latency for the four training trials of that specific day. Mice significantly learned the task as indicated by a reduced time to find the hidden platform. Bonferroni's post hoc analysis showed that all groups learned at the same pace. $B, C$, Reference memory, measured $24 \mathrm{~h}$ after the last training trial, was significantly worse in the $\mathrm{TgTDP}-25$ mice treated with dexamethasone compared with the other two groups clearly showing that in the presence of $\alpha$-lipoic acid, dexamethasone had no effects on spatial memory. The data are presented as means \pm SEM and were analyzed by two-way ANOVA. $n=12 /$ genotype/drug group.

soluble TDP-25 levels. To establish whether there is a causal link between the GSH/GSSG ratio and TDP-25, we injected 6-monthold TgTDP-25 mice daily for 2 weeks with $5 \mathrm{mg} / \mathrm{kg}$ dexamethasone in the presence or absence of $100 \mathrm{mg} / \mathrm{kg} \alpha$-lipoic acid, a dithiol compound known to restore age-dependent changes in the GSH/GSSG ratio in several tissues, including brain (Hagen et al., 2000; Suh et al., 2004). As a control, another group of TgTDP-25 mice were treated with PBS ( $n=12$ /group). At the end of the treatment, mice were trained in the MWM (as described above) to learn to find a hidden platform using extra maze cues. Their performance was analyzed using a mixedmodel, repeated-measures ANOVA, with treatment and genotype as the categorically fixed effects, days as the numeric covariate, animals as the random effect, and escape latency as the dependent variable. We found although the mice significantly learn the task across the $5 \mathrm{~d}$ of training, there was no significant genotype/treatment-day interaction, indicating that there was no difference in the pace of learning among the three groups (Fig. $5 A$ ). Twenty-four hours after the last training trial, we tested spatial memory by measuring the time mice spent in the target quadrant and the number of platform location crosses over a $60 \mathrm{~s}$ probe trial. One-way ANOVA indicated significant changes in the time the mice spent in the target quadrant and the number of platform location crosses (Fig. $5 B, C ; p<0.05$ for both measurements). A post hoc test with Bonferroni correction showed that the TgTDP-25 mice treated with dexamethasone performed significantly worse in both tasks compared with the TgTDP-25 mice injected with PBS or dexamethasone and $\alpha$-lipoic acid $(p<$ $0.05)$. In other words, these data clearly indicate that $\alpha$-lipoic acid prevents the negative effects of dexamethasone on spatial memory in the TgTDP-25 mice.

To determine whether $\alpha$-lipoic acid also prevented the dexamethasone-mediated changes in TDP-25 pathology, we measured TDP-43 and its C-terminal fragments in buffers of increasing strength. We found that the steady-state levels of fulllength TDP-43 were similar among the three groups in both the low- and high-salt fractions (Fig. 6A, $B, D, E$ ). Notably, we found that $\alpha$-lipoic acid prevented the dexamethasone-mediated increase in TDP-25 levels in both low- and high-salt fractions $(p<0.05$; Fig. 

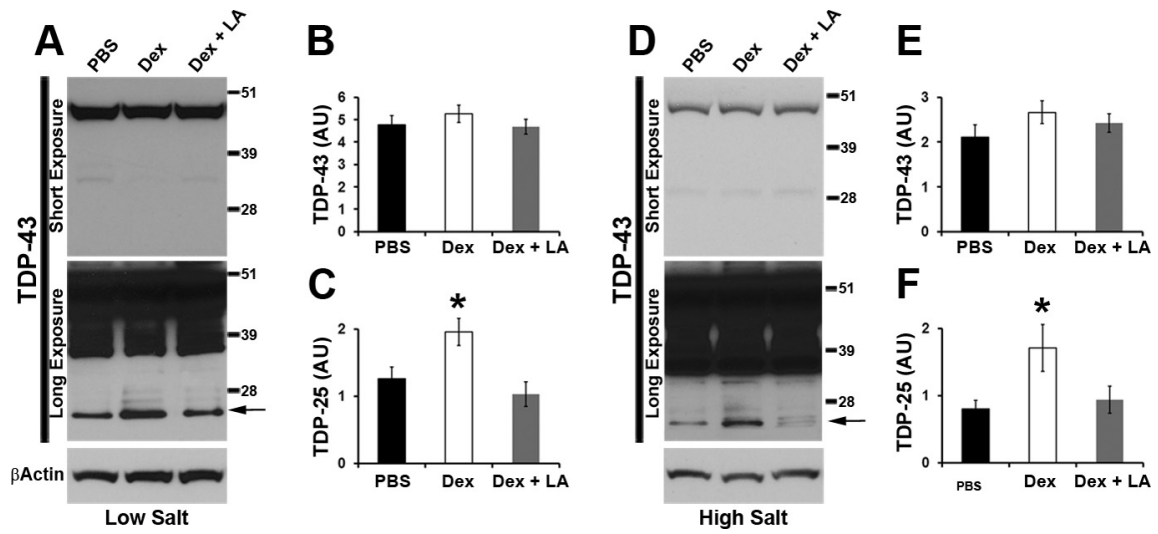

Figure 6. $\quad \alpha$-lipoic acid prevents the dexamethasone-mediated increase in soluble TDP-25 levels. $\boldsymbol{A}$, Representative Western blots of proteins extracted in low-salt buffer from the hippocampi of TgTDP-25 mice treated with PBS, dexamethasone (Dex) or dexamethasone and $\alpha$-lipoic acid (LA). Two different exposure times are presented to show the less abundant, low molecular weight bands. $B$, Quantitative analyses of the blots from low-salt extraction show that the levels of full-length TDP-43 were similar among the three groups of mice. $\boldsymbol{C}$, In contrast, we found that $\alpha$-lipoic acid prevented the dexamethasone-mediated increase in the steady-state levels of TDP-25 (arrow in the bottom blot). $\boldsymbol{D}$, Representative Western blots of proteins extracted from the hippocampi of TgTDP-25 mice in high-salt buffer. Two different exposure times are presented to show the less abundant, low molecular weight bands. $\boldsymbol{E}$, Quantitative analyses of the blots from high-salt extracts show that the levels of full-length TDP-43 were similar among the three different groups. $\boldsymbol{F}$, TDP-25 levels were significantly higher in TgTDP-25 mice treated with dexamethasone; however, $\alpha$-lipoic acid was sufficient to restore the level of TDP-25 (arrow in the bottom blot). $n=8 /$ genotype/treatment group. ${ }^{*} p<0.05$. $\beta$-Actin was used as a loading control and quantifications of the Western blots were done by normalizing the protein of interest to $\beta$-Actin. Data are presented as means \pm SEM and analyzed by one-way ANOVA, with treatment as independent variable. Blots were probed with an anti-TDP-43 polyclonal antibody from Proteintech.
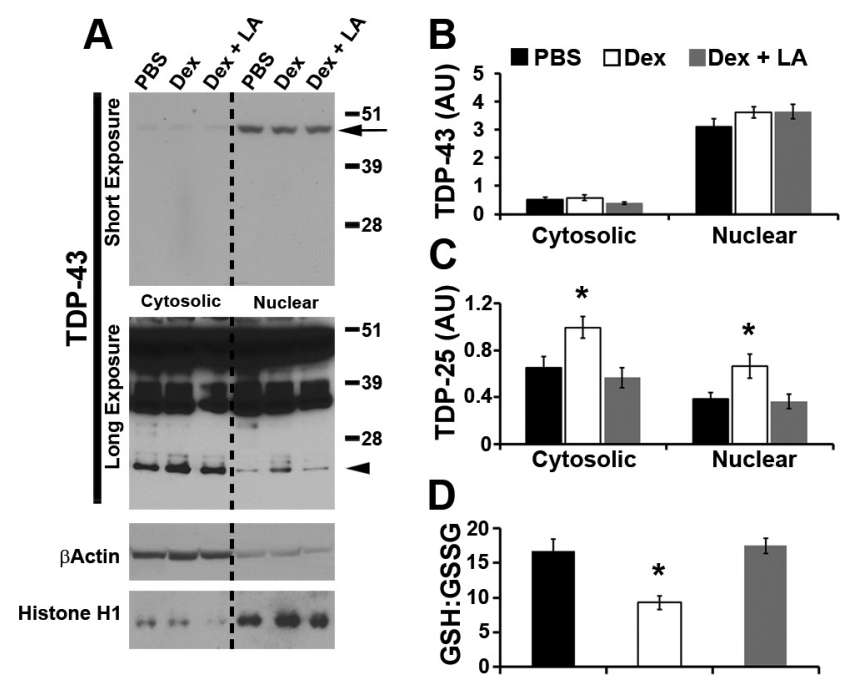

Figure 7. $\alpha$-lipoic acid prevents the dexamethasone-mediated increase in TDP-25 levels in both the nuclear and the cytosolic fraction. $\boldsymbol{A}$, Representative Western blots of protein extracted from the hippocampi of TgTDP-25 treated with PBS or dexamethasone (Dex) in the presence or absence of $\alpha$-lipoic acid (LA). Different exposures are presented to show the less abundant, low molecular weight TDP-43 fragments. Proteins were extracted from the cytosolic and nuclear fractions, as depicted in the figure. TDP-43 blots were probed with an anti-TDP-43 polyclonal antibody from Proteintech. $\beta$-Actin and Histone $\mathrm{H} 1$ were used as loading controls for the cytosolic and nuclear fractions, respectively. $\boldsymbol{B}$, Quantitation of the full-length TDP-43 band (arrow in the top blot of $\boldsymbol{A}$ ) shows that full-length TDP-43 levels were similar among the three different groups. $C$, Quantitative analysis of the $25 \mathrm{kDa}$ band (arrowhead in the bottom blot in $\boldsymbol{A}$ ) shows that $\alpha$-lipoic acid prevented the dexamethasone-mediated increase in TDP-25 levels in both the cytosolic and nuclear fractions. $\boldsymbol{D}$, Consistently, $\alpha$-lipoic acid was also sufficient to prevent the dexamethasone-mediated reduction in the GSH/GSSG ratio. * $p<0.05$. Quantifications of the Western blots were done by normalizing the fragment of interest to $\beta$-Actin or Histone H1. Data are presented as means \pm SEM and analyzed by one-way ANOVA, with treatment group as independent variable. $n=8 /$ genotype/treatment group.
$6 A, C, D, F)$. To determine whether $\alpha$-lipoic acid altered the effects of dexamethasone treatment on the cellular localization of TDP-43, we extracted nuclear and cytosolic fractions from brains of TgTDP-25 treated with dexamethasone in the presence or absence of $\alpha$-lipoic acid. Consistent with the data obtained in the low- and high-salt fractions, we found that $\alpha$-lipoic acid prevented the dexamethasone-mediated increase in TDP-25 levels in the nucleus and the cytosol (Fig. 7A-C). Most notably, $\alpha$-lipoic acid was able to prevent the dexamethasone-induced alterations in the GSH/GSSG ratio (Fig. $7 D)$. Together, these data clearly indicate that the decrease in the GSH/GSSG ratio is necessary for the effects of dexamethasone on TDP-25 levels.

\section{Discussion}

Mutations in the gene encoding TDP-43 are linked to ALS and FTLD (Talbot and Ansorge, 2006; Kabashi et al., 2008; Sreedharan et al., 2008; Valdmanis et al., 2009); however, additional research needs to be conducted to gain mechanistic insights into the molecular mechanisms underlying TDP-43 neuropathology in these disorders. For example, even for familial cases of ALS, the possibility that environmental and endogenous factors may contribute to the disease is not excluded, as most of these cases present with an adult onset (Andersen and AlChalabi, 2011). Thus, one could argue that the penetrance of these disease-causing mutations changes as a function of age, further highlighting that changes occurring during normal aging may precipitate the development of the disease.

Pathologic TDP-43 is mislocalized from its nuclear location to the cytoplasm, where it accumulates. Additionally, the accumulation of the $25 \mathrm{kDa}$ C-terminal fragment of TDP-43 (commonly referred to as TDP-25) is a major neuropathological hallmark of FTLD-TDP (Neumann et al., 2006). We and others have previously shown that the in vitro expression of TDP-25 recapitulates key aspects of TDP-43 proteinopathies (Caccamo et al., 2009; Dormann et al., 2009; Igaz et al., 2009; Nonaka et al., 2009; Zhang et al., 2009). More recently, we have reported the generation of a transgenic mouse model that selectively expresses TDP-25 in neurons. These mice develop cognitive deficits associated with the build-up of soluble TDP-25 (Caccamo et al., 2012). We also reported that the in vivo expression of TDP-25 is sufficient to alter the processing of endogenous full-length TDP-43 (Caccamo et al., 2012). Together, these in vitro and in vivo data strongly indicate that the formation of TDP-25 is a primary event in the pathogenesis of TDP-43 proteinopathies.

Glucocorticoids are steroid hormones secreted from the adrenal gland. In the brain, glucocorticoids regulate the activity of the neuroendocrine and autonomic stress systems (Ulrich-Lai and Herman, 2009). Notably, deregulation of these systems has been associated with brain aging (Garrido, 2011). Additionally, glucocorticoids regulate glucose transport into neurons during stressful events and play a role in cognitive function (Sapolsky, 1999; Joëls et al., 2008). However, excessive glucocorticoid levels increase brain susceptibility to a variety of insults and have been linked to brain aging (Garrido, 2011). In this study, we show that 
dexamethasone, a synthetic glucocorticoid, exacerbates cognitive deficits in the TgTDP-25 mice and increases the soluble levels of TDP-25. Furthermore, we show that dexamethasone treatment leads to higher TDP-25 levels by interfering with the redox status of the cell. Specifically, dexamethasone appears to alter glutathione homeostasis, which leads to an increase in the GSH/GSSG ratio, the primary determinant of the cellular redox state (Rebrin and Sohal, 2008). Given the negative role of glucocorticoids in brain aging and the data presented here, it is tempting to speculate that the age-dependent changes in glucocorticoid levels contribute to the development of TDP-43 proteinopathies.

Glutathione is a primary antioxidant, whose main function is to prevent damage caused by reactive oxygen species (Marí et al., 2009). Additionally, glutathione is involved in detoxifying deleterious substances such as drugs and environmental pollutants as well as enhancing immunological functions (Rebrin and Sohal, 2008). Notably, the GSH/GSSG ratio decreases during aging in mouse brain, an event mainly due to an increase in GSSG levels and a concomitant decrease in GSH synthesis (Suh et al., 2004; Rebrin and Sohal, 2008). Specifically, Suh et al. (2004) reported a $66 \%$ decrease in the GSH/GSSG ratio in the brain of old rats compared with young controls, clearly suggesting that the antioxidant defenses are reduced during aging. This is coupled with an age-dependent increase in the production of mitochondrial superoxide and hydrogen peroxide (Sohal and Sohal, 1991; Sohal et al., 1994, 2002). In vitro data from two independent groups have shown that oxidative stress induced by glutathione depletion or increase in hydrogen peroxide contribute to TDP-43 pathology (Cohen et al., 2011b; Iguchi et al., 2012). Specifically, Cohen et al. (2011b) showed that alterations in the redox signaling directly regulate TDP-43 metabolism, which is highly consistent with the data presented here. Together, these published reports and the data presented here suggest that oxidative damage, occurring during normal aging or induced by stress hormones, may contribute to the pathogenesis of TPD-43 proteinopathies.

In summary, the data presented here provide the first in vivo evidence of external factors altering the pathogenesis of TDP-43 proteinopathies, such as ALS and FTLD. Our data have major implications regarding the effects of aging on the pathogenesis of these disorders, as we show that glucocorticoids, whose levels change as a function of age, exacerbate cognitive deficits and increase TPD-25 levels in transgenic mice. These results suggest that compounds aimed at controlling glucocorticoid levels may delay or slow down the progression of TDP-43 proteinopathies.

\section{References}

Andersen PM, Al-Chalabi A (2011) Clinical genetics of amyotrophic lateral sclerosis: what do we really know? Nat Rev Neurol 7:603-615. CrossRef Medline

Ballatori N, Krance SM, Notenboom S, Shi S, Tieu K, Hammond CL (2009) Glutathione dysregulation and the etiology and progression of human diseases. Biol Chem 390:191-214. Medline

Bose JK, Huang CC, Shen CK (2011) Regulation of autophagy by neuropathological protein TDP-43. J Biol Chem 286:44441-44448. CrossRef Medline

Brady OA, Meng P, Zheng Y, Mao Y, Hu F (2011) Regulation of TDP-43 aggregation by phosphorylation and p62/SQSTM1. J Neurochem 116: 248-259. CrossRef Medline

Buratti E, Baralle FE (2008) Multiple roles of TDP-43 in gene expression, splicing regulation, and human disease. Front Biosci 13:867-878. CrossRef Medline

Caccamo A, Majumder S, Deng JJ, Bai Y, Thornton FB, Oddo S (2009) Rapamycin rescues TDP-43 mislocalization and the associated low molecular mass neurofilament instability. J Biol Chem 284:27416-27424. CrossRef Medline
Caccamo A, Magrí A, Oddo S (2010a) Age-dependent changes in TDP-43 levels in a mouse model of Alzheimer disease are linked to Abeta oligomers accumulation. Mol Neurodegener 5:51. CrossRef Medline

Caccamo A, Maldonado MA, Bokov AF, Majumder S, Oddo S (2010b) CBP gene transfer increases BDNF levels and ameliorates learning and memory deficits in a mouse model of Alzheimer's disease. Proc Natl Acad Sci U S A 107:22687-22692. CrossRef Medline

Caccamo A, Majumder S, Oddo S (2012) Cognitive decline typical of frontotemporal lobar degeneration in transgenic mice expressing the $25-\mathrm{kDa}$ C-terminal fragment of TDP-43. J Pathol 180:293-302.

Clinton LK, Billings LM, Green KN, Caccamo A, Ngo J, Oddo S, McGaugh JL, LaFerla FM (2007) Age-dependent sexual dimorphism in cognition and stress response in the 3xTg-AD mice. Neurobiol Dis 28:76-82. CrossRef Medline

Cohen TJ, Lee VM, Trojanowski JQ (2011a) TDP-43 functions and pathogenic mechanisms implicated in TDP-43 proteinopathies. Trends Mol Med 17:659-667. CrossRef Medline

Cohen TJ, Hwang AW, Unger T, Trojanowski JQ, Lee VM (2011b) Redox signalling directly regulates TDP-43 via cysteine oxidation and disulphide cross-linking. EMBO J 31:1241-1252. CrossRef Medline

Dormann D, Capell A, Carlson AM, Shankaran SS, Rodde R, Neumann M, Kremmer E, Matsuwaki T, Yamanouchi K, Nishihara M, Haass C (2009) Proteolytic processing of TAR DNA binding protein- 43 by caspases produces $\mathrm{C}$-terminal fragments with disease defining properties independent of progranulin. J Neurochem 110:1082-1094. CrossRef Medline

Garrido P (2011) Aging and stress: past hypotheses, present approaches and perspectives. Aging Dis 2:80-99. Medline

Geser F, Lee VM, Trojanowski JQ (2010) Amyotrophic lateral sclerosis and frontotemporal lobar degeneration: a spectrum of TDP-43 proteinopathies. Neuropathology 30:103-112. CrossRef Medline

Ghezzi P (2005) Regulation of protein function by glutathionylation. Free Radic Res 39:573-580. CrossRef Medline

Green KN, Billings LM, Roozendaal B, McGaugh JL, LaFerla FM (2006) Glucocorticoids increase amyloid-beta and tau pathology in a mouse model of Alzheimer's disease. J Neurosci 26:9047-9056. CrossRef Medline

Hagen TM, Vinarsky V, Wehr CM, Ames BN (2000) (R)-alpha-lipoic acid reverses the age-associated increase in susceptibility of hepatocytes to tert-butylhydroperoxide both in vitro and in vivo. Antioxid Redox Signal 2:473-483. CrossRef Medline

Hasegawa M, Nonaka T, Tsuji H, Tamaoka A, Yamashita M, Kametani F, Yoshida M, Arai T, Akiyama H (2011) Molecular dissection of TDP-43 proteinopathies. J Mol Neurosci 45:480-485. CrossRef Medline

Igaz LM, Kwong LK, Xu Y, Truax AC, Uryu K, Neumann M, Clark CM, Elman LB, Miller BL, Grossman M, McCluskey LF, Trojanowski JQ, Lee VM (2008) Enrichment of C-terminal fragments in TAR DNA-binding protein- 43 cytoplasmic inclusions in brain but not in spinal cord of frontotemporal lobar degeneration and amyotrophic lateral sclerosis. Am J Pathol 173:182-194. CrossRef Medline

Igaz LM, Kwong LK, Chen-Plotkin A, Winton MJ, Unger TL, Xu Y, Neumann M, Trojanowski JQ, Lee VM (2009) Expression of TDP-43 C-terminal fragments in vitro recapitulates pathological features of TDP-43 proteinopathies. J Biol Chem 284:8516-8524. Medline

Iguchi Y, Katsuno M, Takagi S, Ishigaki S, Niwa J, Hasegawa M, Tanaka F, Sobue G (2012) Oxidative stress induced by glutathione depletion reproduces pathological modifications of TDP-43 linked to TDP-43 proteinopathies. Neurobiol Dis 45:862-870. CrossRef Medline

Joëls M, Krugers H, Karst H (2008) Stress-induced changes in hippocampal function. Prog Brain Res 167:3-15. Medline

Kabashi E, Valdmanis PN, Dion P, Spiegelman D, McConkey BJ, Vande Velde C, Bouchard JP, Lacomblez L, Pochigaeva K, Salachas F, Pradat PF, Camu W, Meininger V, Dupre N, Rouleau GA (2008) TARDBP mutations in individuals with sporadic and familial amyotrophic lateral sclerosis. Nat Genet 40:572-574. CrossRef Medline

Lee EB, Lee VM, Trojanowski JQ (2012) Gains or losses: molecular mechanisms of TDP43-mediated neurodegeneration. Nat Rev Neurosci 13:38-50. Medline

Lein ES, Hawrylycz MJ, Ao N, Ayres M, Bensinger A, Bernard A, Boe AF, Boguski MS, Brockway KS, Byrnes EJ, Chen L, Chen L, Chen TM, Chin MC, Chong J, Crook BE, Czaplinska A, Dang CN, Datta S, Dee NR, et al. (2007) Genome-wide atlas of gene expression in the adult mouse brain. Nature 445:168-176. CrossRef Medline 
Marí M, Morales A, Colell A, García-Ruiz C, Fernández-Checa JC (2009) Mitochondrial glutathione, a key survival antioxidant. Antioxid Redox Signal 11:2685-2700. CrossRef Medline

McIntosh LJ, Hong KE, Sapolsky RM (1998) Glucocorticoids may alter antioxidant enzyme capacity in the brain: baseline studies. Brain Res 791: 209-214. CrossRef Medline

Medina DX, Caccamo A, Oddo S (2011) Methylene blue reduces abeta levels and rescues early cognitive deficit by increasing proteasome activity. Brain Pathol 21:140-149. CrossRef Medline

Meyerowitz J, Parker SJ, Vella LJ, Ng DCh, Price KA, Liddell JR, Caragounis A, Li QX, Masters CL, Nonaka T, Hasegawa M, Bogoyevitch MA, Kanninen KM, Crouch PJ, White AR (2011) C-Jun N-terminal kinase controls TDP-43 accumulation in stress granules induced by oxidative stress. Mol Neurodegener 6:57. CrossRef Medline

Mizushima N, Noda T, Yoshimori T, Tanaka Y, Ishii T, George MD, Klionsky DJ, Ohsumi M, Ohsumi Y (1998) A protein conjugation system essential for autophagy. Nature 395:395-398. CrossRef Medline

Neumann M, Sampathu DM, Kwong LK, Truax AC, Micsenyi MC, Chou TT, Bruce J, Schuck T, Grossman M, Clark CM, McCluskey LF, Miller BL, Masliah E, Mackenzie IR, Feldman H, Feiden W, Kretzschmar HA, Trojanowski JQ, Lee VM (2006) Ubiquitinated TDP-43 in frontotemporal lobar degeneration and amyotrophic lateral sclerosis. Science 314:130-133. CrossRef Medline

Nonaka T, Kametani F, Arai T, Akiyama H, Hasegawa M (2009) Truncation and pathogenic mutations facilitate the formation of intracellular aggregates of TDP-43. Hum Mol Genet 18:3353-3364. CrossRef Medline

Oddo S, Caccamo A, Cheng D, Jouleh B, Torp R, LaFerla FM (2007) Genetically augmenting tau levels does not modulate the onset or progression of Abeta pathology in transgenic mice. J Neurochem 102:1053-1063. CrossRef Medline

Ohsumi Y (2001) Molecular dissection of autophagy: two ubiquitin-like systems. Nat Rev Mol Cell Biol 2:211-216. CrossRef Medline

Patel R, McIntosh L, McLaughlin J, Brooke S, Nimon V, Sapolsky R (2002) Disruptive effects of glucocorticoids on glutathione peroxidase biochemistry in hippocampal cultures. J Neurochem 82:118-125. CrossRef Medline

Pivtoraiko VN, Stone SL, Roth KA, Shacka JJ (2009) Oxidative stress and autophagy in the regulation of lysosome-dependent neuron death. Antioxid Redox Signal 11:481-496. CrossRef Medline

Puccio S, Chu J, Praticò D (2011) Involvement of 5-lipoxygenase in the corticosteroid-dependent amyloid beta formation: in vitro and in vivo evidence. PLoS One 6:e15163. CrossRef Medline

Reagan LP, McEwen BS (1997) Controversies surrounding glucocorticoidmediated cell death in the hippocampus. J Chem Neuroanat 13:149-167. CrossRef Medline

Rebrin I, Sohal RS (2008) Pro-oxidant shift in glutathione redox state during aging. Adv Drug Deliv Rev 60:1545-1552. CrossRef Medline

Sapolsky RM (1996) Stress, glucocorticoids, and damage to the nervous system: the current state of confusion. Stress 1:1-19. CrossRef Medline

Sapolsky RM (1999) Glucocorticoids, stress, and their adverse neurological effects: relevance to aging. Exp Gerontol 34:721-732. CrossRef Medline

Sarabdjitsingh RA, Joëls M, de Kloet ER (2012) Glucocorticoid pulsatility and rapid corticosteroid actions in the central stress response. Physiol Behav 106:73-80. CrossRef Medline

Sohal RS, Sohal BH (1991) Hydrogen peroxide release by mitochondria increases during aging. Mech Ageing Dev 57:187-202. CrossRef Medline

Sohal RS, Ku HH, Agarwal S, Forster MJ, Lal H (1994) Oxidative damage, mitochondrial oxidant generation and antioxidant defenses during aging and in response to food restriction in the mouse. Mech Ageing Dev 74: 121-133. CrossRef Medline
Sohal RS, Mockett RJ, Orr WC (2002) Mechanisms of aging: an appraisal of the oxidative stress hypothesis. Free Radic Biol Med 33:575-586. CrossRef Medline

Sotiropoulos I, Catania C, Pinto LG, Silva R, Pollerberg GE, Takashima A, Sousa N, Almeida OF (2011) Stress acts cumulatively to precipitate Alzheimer's disease-like tau pathology and cognitive deficits. J Neurosci 31: 7840-7847. CrossRef Medline

Sreedharan J, Blair IP, Tripathi VB, Hu X, Vance C, Rogelj B, Ackerley S, Durnall JC, Williams KL, Buratti E, Baralle F, de Belleroche J, Mitchell JD, Leigh PN, Al-Chalabi A, Miller CC, Nicholson G, Shaw CE (2008) TDP-43 mutations in familial and sporadic amyotrophic lateral sclerosis. Science 319:1668-1672. CrossRef Medline

Suh JH, Wang H, Liu RM, Liu J, Hagen TM (2004) (R)-alpha-lipoic acid reverses the age-related loss in GSH redox status in post-mitotic tissues: evidence for increased cysteine requirement for GSH synthesis. Arch Biochem Biophys 423:126-135. CrossRef Medline

Suzuki K, Kirisako T, Kamada Y, Mizushima N, Noda T, Ohsumi Y (2001) The pre-autophagosomal structure organized by concerted functions of APG genes is essential for autophagosome formation. EMBO J 20:5971-5981. CrossRef Medline

Talbot K, Ansorge O (2006) Recent advances in the genetics of amyotrophic lateral sclerosis and frontotemporal dementia: common pathways in neurodegenerative disease. Hum Mol Genet 15 Spec No 2:R182-R187.

Terzic N, Vujcic M, Ristic-Fira A, Krstic-Demonacos M, Milanovic D, Kanazir DT, Ruzdijic S (2003) Effects of age and dexamethasone treatment on glucocorticoid response element and activating protein- 1 binding activity in rat brain. J Gerontol A Biol Sci Med Sci 58:297-303. Medline

Ulrich-Lai YM, Herman JP (2009) Neural regulation of endocrine and autonomic stress responses. Nat Rev Neurosci 10:397-409. CrossRef Medline

Urushitani M, Sato T, Bamba H, Hisa Y, Tooyama I (2010) Synergistic effect between proteasome and autophagosome in the clearance of polyubiquitinated TDP-43. J Neurosci Res 88:784-797. Medline

Valdmanis PN, Daoud H, Dion PA, Rouleau GA (2009) Recent advances in the genetics of amyotrophic lateral sclerosis. Curr Neurol Neurosci Rep 9:198-205. CrossRef Medline

Wang HY, Wang IF, Bose J, Shen CK (2004) Structural diversity and functional implications of the eukaryotic TDP gene family. Genomics 83:130 139. CrossRef Medline

Wang IF, Reddy NM, Shen CK (2002) Higher order arrangement of the eukaryotic nuclear bodies. Proc Natl Acad Sci U S A 99:13583-13588. CrossRef Medline

Wang IF, Wu LS, Chang HY, Shen CK (2008) TDP-43, the signature protein of FTLD-U, is a neuronal activity-responsive factor. J Neurochem 105: 797-806. CrossRef Medline

Wang IF, Guo BS, Liu YC, Wu CC, Yang CH, Tsai KJ, Shen CK (2012) Autophagy activators rescue and alleviate pathogenesis of a mouse model with proteinopathies of the TAR DNA-binding protein 43. Proc Natl Acad Sci U S A 109:15024-15029. CrossRef Medline

Wang X, Fan H, Ying Z, Li B, Wang H, Wang G (2010) Degradation of TDP-43 and its pathogenic form by autophagy and the ubiquitinproteasome system. Neurosci Lett 469:112-116. CrossRef Medline

Yao YY, Wu QS, Li WZ, Li WP (2011) Dexamethasone potentiated Abeta-induced learning and memory impairment in rats. Neurol Res 33:371-380. CrossRef Medline

Zhang YJ, Xu YF, Cook C, Gendron TF, Roettges P, Link CD, Lin WL, Tong J, Castanedes-Casey M, Ash P, Gass J, Rangachari V, Buratti E, Baralle F, Golde TE, Dickson DW, Petrucelli L (2009) Aberrant cleavage of TDP-43 enhances aggregation and cellular toxicity. Proc Natl Acad Sci U S A 106:7607-7612. CrossRef Medline 